\title{
Development and Study of the Structure and Properties of a Composite Textile Material with Encapsulated Heat-Preserving Components for Heat-Protective Clothing
}

\author{
Irina Cherunova ${ }^{1,2, * \mathbb{D}}$, Nikolai Kornev ${ }^{2} \mathbb{D}$, Ekaterina Lukyanova ${ }^{1}$ and Valery Varavka ${ }^{3}$ \\ 1 Department of Technology and Design, Don State Technical University, Shevchenko-Str. 147, \\ 346500 Shakhty, Russia; el_s@list.ru \\ 2 Chair of Modelling and Simulation, University of Rostock, Albert-Einstein-Str. 2, 18059 Rostock, Germany; \\ nikolai.kornev@uni-rostock.de \\ 3 Research and Education Center "Materials", Don State Technical University, Gagarin sq., 1, \\ 344000 Rostov-on-Don, Russia; varavkavn@gmail.com \\ * Correspondence: i_sch@mail.ru; Tel.: +7-8636237222
}

Citation: Cherunova, I.; Kornev, N.; Lukyanova, E.; Varavka, V. Development and Study of the Structure and Properties of a Composite Textile Material with Encapsulated Heat-Preserving Components for Heat-Protective Clothing. Appl. Sci. 2021, 11, 5247. https://doi.org/10.3390/app11115247

Academic Editor: Rocco Furferi

Received: 26 April 2021

Accepted: 29 May 2021

Published: 4 June 2021

Publisher's Note: MDPI stays neutral with regard to jurisdictional claims in published maps and institutional affiliations.

Copyright: (c) 2021 by the authors. Licensee MDPI, Basel, Switzerland. This article is an open access article distributed under the terms and conditions of the Creative Commons Attribution (CC BY) license (https:// creativecommons.org/licenses/by/ $4.0 /)$.

\begin{abstract}
The modern technology of heat-protective clothing is increasingly aimed at maintaining the active function of materials. Adding heat-preserving components into the volume of heat-insulating fibrous materials changes their structure and properties. In this article, the methods of forming the structure of multi-component insulants with heat-preserving components, as well as the study of structural and thermophysical properties, are presented. Composite textile materials were used in this study, namely a $0 / 30 / 50 / 100 \%$ Outlast textile (based on polyester fleece, $70 \%$ ) + Termofiber (fiberinsulated polyester material, $100 \%$ ). Based on the research, we established the structural parameters of Termofiber fibrous canvas and the Outlast textile. The study of the thermal conductivity of complex combined insulation materials was performed for different temperature conditions (up to $+25^{\circ} \mathrm{C}$ ) and for the proportion of the heat-accumulating textile components. Based on the obtained research results for the development of complex materials from Termofiber + the Outlast textile, the fraction of the Outlast textile component should be limited to no more than $40 \%$ for textile shells in clothing that are operated at a temperature of $+5^{\circ} \mathrm{C}$ or below. Further conditions for determining the composition of the studied materials for clothing can be settled by taking into account the density of the materials, the mass, and the general thermal insulation of clothing.
\end{abstract}

Keywords: textile materials; fibrous structure; heat-protective clothing PCM; thermal properties

\section{Introduction}

There is currently a wide range of textile materials available for the manufacture of heat-protective clothing. The main function of clothing to protect against the cold is provided by voluminous, fibrous materials. These materials ensure thermal resistance to the cold due to their thickness [1] and the internal inert air contained within the material [2]. This is the passive function of heat-insulating materials and clothes. However, the modern technology of heat-protective clothing is increasingly aimed at developing the active function of such materials. This function is based on the preservation and subsequent use of the human's inner heat in the clothing [3], using additional functional components in composite materials [4]. As functional components of such materials, materials with phase changes and heat-preserving properties are used [5]. Adding heat-preserving components in the volume of heat-insulating fibrous materials changes their structure and properties that should be taken into account and predicted at the design stage of materials and clothing made of such materials. Despite the availability of scientific papers in this field [6], most of them are devoted to physical and chemical properties [7], rather than the structure and physical properties. Various salts and chemical compounds are currently used as heat-preserving components. To be used in clothing, such materials must be compatible 
with fibrous components and must be protected against active substance volume loss. Meanwhile, composite materials that contain two or more components in their structure have their own complex structure and thermophysical properties that require additional research. There are studies of individual heat-preserving substances and their addition into thin layers of clothing [8]. However, complex voluminous heat-preserving materials with functional components are of great relevance for science and production technology. Therefore, to support the processes for the design of new functional materials and their application in clothing, we need to develop methods of forming the structure of multicomponent insulants with heat-preserving components, and we need to study and describe their main characteristics and properties: structural and thermophysical.

The novelty of the present work is the discovery of the proper composition of materials which fulfills the requirements of necessary heat conduction and does not exceed the thickness limitations for the clothing. The addition of the PCMs leads to a change in the thermal conductivity. If it results in a growth in the conductivity, then an increase in the thickness of clothing is required to maintain thermal insulation. Increased thickness is not desirable because it leads to a reduction in the operational quality of clothing. Therefore, the limitation of thickness leads to a limitation for the thermal conductivity of the materials used and for the fraction of the PCMs. The determination of this fraction is the aim of this work.

\section{Materials and Methods}

\subsection{Materials}

\subsubsection{Materials in the Closing Shells}

Heat-protective clothing includes two or more layers of textile materials, the simplest composition of which includes three layers: first, a thin outer clothing cover material; second, a voluminous, soft heat-insulating material (this can be composed of several materials); and third, a thin material (back-cloth) [9]. A heat reserve in the layers of clothing, which must be created through the use of heat-preserving materials, can be obtained both from external physical sources of environmental heat (e.g., a warm room) and from the human's biological heat. The heat reserve created in the clothing must be protected from the rapid penetration of the cold into the layers of the materials. The outer cover of the clothing (M1) is oriented by its surface towards the cold. It must create a primary mechanical barrier and maintain the geometric boundaries of the clothing cover due to its elastic properties. This allows for the maintenance of the internal dimensions and the volume of the soft heat-insulating materials. The inner layers of materials, which are encased within a cover with a relatively constant volume, are the main source of thickness for the clothing. That is, it is the voluminous heat-insulating (M2) and internal back-cloth (M3) materials that are considered fibrous canvases for adding phase change materials (PCMs) into their structure, as they are oriented toward the heat flow inside the clothing (Figure 1).

At the same time, materials in the M2 group may have their own several layers of complex compound structures [9]. Textile materials with integrated PCMs are called materials with heat-preserving materials (HPMs).

Thus, in the corresponding material layers, different functions are provided:

M1- functions as the main barrier protection against harmful environmental factors (production processes and weather), preserves and maintains the clothing shape and size;

M2- provides thermal insulation and thermoregulation (including heat-preservation);

M3 - allows for moisture exchange, thermic regulation (including heat-preservation), and surface sliding. 


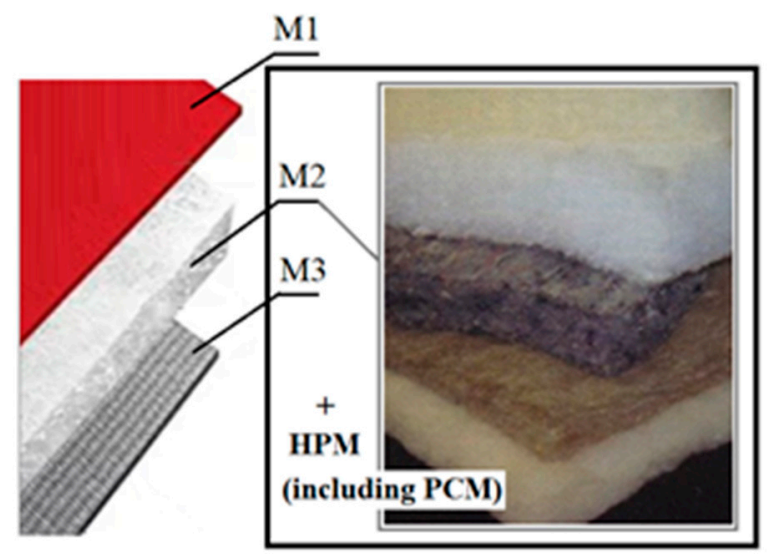

(a)

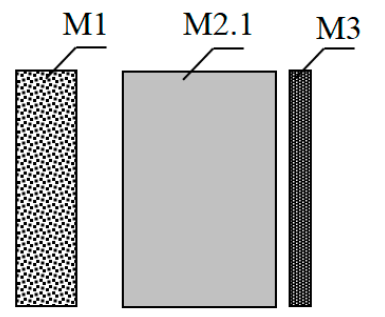

(b)

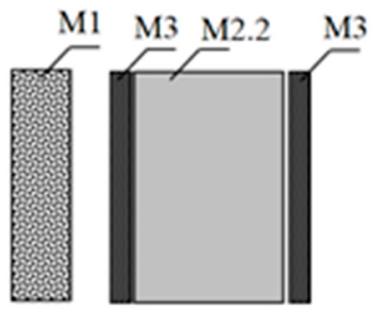

(c)

Figure 1. Material configuration layout of heat-protective clothing: (a) samples of materials included; (b) a set with the continuous insulation; (c) a set with a loose fiber mixture insulation. M1, the outer material of the cover; M2, the heat-insulating material (it can be multi-layered), M2.1, the continuous canvas and M2.2, the loose fiber mixture; M3, the back-cloth material; HPMs, the heat-preserving materials (including PCMs).

The M2 material group is represented by high-porosity, voluminous, fibrous materials. This material layer can be represented by one material or a group of materials of the "continuous canvas" type (M2.1). Another version of the M2 layer can be made using loose materials in the form of fibrous mixtures that have no constant shape or size of their canvas (M.2.2) but fill a given volume between the materials with their particles, such as M1 and M3, in special clothing compartments. These compartments are formed from thin, high-density lining fabrics to prevent the migration of loose fibers from the inner layer of a compartment to the outer surface of the clothing. Therefore, the methods of forming a set of materials in clothing depend on the type of insulation materials used (continuous canvases or loose insulants).

In order to integrate HPM components into heat-protective materials in a way that maintains necessary functions, we have studied a wide range of modern fibrous materials of the M2 group, including batting, sherston, sintepon, Orsotherm, Termotec, Fibertec, Thinsulate, Hollofiber, Termofiber, Hollotec, Arctic, wool felt, Hollophane, Thermofin, Isosoft, Thermolight, Nonwoven, Microfine (in canvas and in a mixture), Valtherm, Shersticron, a natural down mixture, a loose hollofiber mixture, Primaloft, Termofiber Micro, Shelter, and various fleeces. Our analyses of the fiber composition of the studied materials showed that most modern heat-insulating materials are based on polyester fibers connected in various ways, whereas, in terms of the shape, the predominant materials used are those of the "solid continuous canvas" type. It is these materials that require the development of new methods to give them functional properties.

For further studies, we have chosen Termofiber as a reference sample of the voluminous, fibrous material [10]. It is of the "solid continuous canvas" types made of $100 \%$ polyester fibers. 
The systematization of the parameters of the M3 group materials showed that they feature a small degree of thickness and a relatively high density [11]; therefore, it is very difficult to integrate HPM components into such ready-made materials. They are made by adding HPMs at the primary production stage using nonwoven or knitted technology.

\subsubsection{Heat-Accumulating Components}

Heat-preserving materials (HPMs) are characterized by phase change properties. Heat is spent on a phase change, which is often associated with the melting of the main constituent substance. Upon a reverse change in the temperature effect on the main active HPM, the substance is again solidified. These HPMs feature a fairly high specific energy [12].

HPMs of various types are widely used, including various phase change substances (PCMs), which are embedded in the dispersion form in the polymer matrix [13], as well as organic gels and hydrogels [14]. However, for the integration into textiles and further use in clothing, it is important to fix the volume of the active HPM size, shape, and resistance to establish contact with other fibrous components of materials. Therefore, PCM encapsulation methods, using covers of high molecular weight compounds, have become widespread for these purposes. A requirement of the heat accumulators with phase changes is the use of a special composition of the active substance for each of the required temperature values.

Taken from the research and systematization of the temperature properties of modern PCMs [15-17], their systematization is given in Table 1.

Table 1. Melting/stabilization temperature parameters of substances and materials with heatpreserving properties.

\begin{tabular}{ll}
\hline \multicolumn{1}{c}{ Mixture Composition } & Melting Temperature, ${ }^{\circ} \mathbf{C}$ \\
\hline Pentadecan & +9.9 \\
Dakotan & +44 \\
Heptadecan & +22 \\
Heneicosan & +40 \\
Octadecan & $+26 \ldots+25.8$ \\
Tetradecan & $+27 \ldots+25.5$ \\
Dakotan octadecan & $+31.2 \ldots+38.4$ \\
Octadecan heneicosan & $+35.0 \ldots+42.2$ \\
Palmitic acid & $+53.0 \ldots+80.0$ \\
Nonadecane & $+50 \ldots+55$ \\
Aktekin & +48 \\
Heat-accumulating composition RU 2239647 [18] & +32.5 \\
Heat-accumulating composition RU 2190656 [19] & +33.4 \\
Sodium thiosulfate pentahydrate & $+22 \ldots+36.1$ \\
Sodium sulfate decahydrate (Glauber's salt) & +58.0 \\
Sodium sulfite heptahydrate & +53.4 \\
Sodium carbonate decahydrate & +55.4 \\
Sodium acetate trihydrate & +52.6 \\
Paraffin & $+25 \ldots+50$ \\
\hline
\end{tabular}

Our analyses of materials with a phase change (PCMs) showed that heat-preserving materials that can store heat within the temperature range of 20 to $40{ }^{\circ} \mathrm{C}$ have found the widest technological application in the form of microcapsules in fibrous materials. When the temperature rises above 35 or $40^{\circ} \mathrm{C}$, microencapsulated systems absorb heat; whereas, at temperatures below $20^{\circ} \mathrm{C}$, they release the absorbed heat into the environment.

The melting point analyses of pure saturated hydrocarbons and their mixtures, as presented in Table 1, have allowed us to isolate substances-such as octadecane and its compounds (heneicosane-octadecane, docosane-octadecane, octadecane-heneicosane-palmitic acid), nonadecane, eicodecane, sodium sulfate decahydrate (Glauber's salt), heptadecane, and sodium sulfite heptahydrate-that, in terms of their temperature properties, most 
correspond to the phase change thermal conditions and the characteristic temperature of the human body in heat-protective clothes.

For the relevant temperature range, the materials that are being widely used in the world are Micronal ${ }^{\circledR}$ PCMs, which are based on microcapsules from a special group of paraffins and Glauber's salt, as developed and implemented by BASF [20]. Micronal ${ }^{\circledR}$ PCMs can be used in the dispersion of the microcapsules therein. A phase change (melting) of this material occurs at a temperature of $+25 \pm 1{ }^{\circ} \mathrm{C}$ (the main peak) and another phase change (crystallization) occurs at $+24 \pm 1{ }^{\circ} \mathrm{C}$ (the main peak); the melting heat is within the range of 10 to $35^{\circ} \mathrm{C} \geq 97 \mathrm{~J} / \mathrm{g}$ [20]. However, this material is currently adapted mainly for building materials.

The analysis of world developments in the field of encapsulation methods for materials with a phase change made it possible to identify the most effective methods for textile technology.

PureTemp, a Japanese encapsulated material [21], is used as a cover for textile fabric, thereby creating an additional layer with a heat-preserving effect. The PureTemp phase change material is enclosed in spherical microcapsules and, using a patented method, these microcapsules are bound to the textile material surface. However, such a continuous coating has limitations for direct use as a voluminous, fibrous heat-insulating material within the M2 group (Figure 1), which requires a high level of porosity. There are bicomponent fibers-PCM64-that can be mixed with PCMs. This PCM64 bico mixture is enclosed inside the fiber core. Fibers in such materials have a diameter of about $35 \mu \mathrm{m}$. German, Chinese, and Japanese developers and manufacturers have made significant developments in this field [22-25]. Among them, special mention should be made of the materials created using Outlast Technologies [25]. This group of textile materials with integrated PCMs has found application in space technology and is increasingly used in the production of heat-protective clothing. A feature of such materials is the possibility of introducing active capsules into the fibrous textile materials of complex, multi-layer structures of HPMs [25].

\subsubsection{Materials Used in the Study}

For voluminous heat-insulating materials of the M2 group, promising areas lie within the development and research of a system of materials consisting of two or more components-one of which is a heat-insulating material based on non-woven, voluminous textile materials. In this system, functional components are parts of heatpreserving, microencapsulated HPMs of various sizes, volume fractions, and structural combinations within the canvas. As the main active component for the study of such a system, we selected the textile material HPM based on Outlast Technologies.

As a heat-accumulating component, the composite material from Outlast textiles, with the inclusion of Outlast fibers in the polyester matrix, was used. The Outlast material contains PU capsules that have paraffins with phase changes at a temperature of $+25^{\circ} \mathrm{C}$ or more (according to Table 1) and have a latent heat value of $115-130 \mathrm{~kJ} / \mathrm{kg}$ [25].

The characteristics of the materials illustrated in Figure 1 are shown in Table 2.

Table 2. Parameters of material samples used for research.

\begin{tabular}{cccc}
\hline Material Category * & Priority Fiber & $\begin{array}{c}\text { Coupling with Heat-Accumulating } \\
\text { Textile Components }\end{array}$ & $\begin{array}{c}\text { Material for the Test } \\
\text { Complex Test Sample }\end{array}$ \\
\hline M1 & $\begin{array}{c}\text { Polyester, cotton, including } \\
\text { their combination }\end{array}$ & - & Termofiber + (Outlast textile) \\
\hline M2.1 & Polyester, Outlast & + & - \\
\hline M2.2 & Polyester, down & {$[20,21,23-25]$} & \\
\hline M3 & & $*$
\end{tabular}


A compound insulating material that consists of two or more components of different structures has its own thermophysical properties. Composite textile materials were used in this study, namely a $0 / 30 / 50 / 100 \%$ Outlast textile (based on polyester fleece, $70 \%$ ) + Termofiber (fiber-insulated polyester material, 100\%). Outlast yarn incorporates thermally active material (i.e., paraffinic phase change material (PCM) microcapsules) within the polyester fiber structure, according to Outlast technology, and the thermo-regulating effect results either from the heat absorption or heat emission of the PCMs [26]. Table 3.

The characteristics of the insulating materials sampled for research are presented in

Table 3. Characteristics of materials sampled for research.

\begin{tabular}{|c|c|c|c|c|c|}
\hline $\begin{array}{c}\text { № of } \\
\text { Materials }\end{array}$ & Material & $\begin{array}{l}\text { Composition of Fibers and } \\
\text { Polymer Components, } \%\end{array}$ & Density, $\mathrm{kg} / \mathrm{m}^{3}$ & $\begin{array}{l}\text { Features of the } \\
\text { Material Structure }\end{array}$ & Thickness, $\mathrm{m}$ \\
\hline 1 & Termofiber & Polyester, 100 & 14.2 & Nonwoven fabric & $0.001 \ldots 0.021$ \\
\hline 2 & Outlast textile & $\begin{array}{l}\text { Outlast, } 30+ \\
\text { Polyester, } 70\end{array}$ & 238.0 & Outlast fleece & 0.00085 \\
\hline
\end{tabular}

The different compositions of Termofiber/Outlast textile samples used in the present research, in \%, are:

(1) $100 / 0$;

(2) $70 / 30$;

(3) $50 / 50$;

(4) $0 / 100$.

\subsection{Methods}

To define the criteria for interfacing the presented base components (Termofiber) and the functional HPMs (Outlast textile), we studied both using microstructural analysis methods [26]. For this purpose, we used optical and electron microscopy methods.

The study of the fibrous structure of the bonded Termofiber canvas was conducted using special equipment: a Keyence VHX5000 microscope [27]. Its design provides magnification from $0.1 \times$ to $5000 \times$, whereas the availability of a highly sensitive camera, the high processing speed of graphic images, and horizontal and vertical viewing angles up to $\pm 89^{\circ}$ allowed us to perform a quantitative and qualitative assessment of the $2 \mathrm{D}$ and $3 \mathrm{D}$ digital parameters of the studied fiber structure.

To study the microstructure of Outlast encapsulated material, we used the methodological and technical resources of a two-beam scanning electron/ion microscope-a ZEISS CrossBeam 340 [27]. The crossbeam in the microscope design combines a versatile platform with a camera and is based on the GEMINI technology. This technology made it possible to analyze the structure of the textiles at the level of microcapsule parameters with a phase change. Using a turbo evaporator device, samples were prepared for examination by electron microscopy.

The heat-protective textile materials that are used in the production of clothing have a thermal conductivity of no more than $1.5 \mathrm{~W} / \mathrm{mK}$ [27]. This allows us to use the stationary thermal regime method for experimental research [28]. The research of thermophysical properties is based on the methods of the experimental study of the heat conductivity of fibrous materials, and uses the data analysis of heat flow measurements, which are recorded in a stationary mode with a temperature gradient [28]. The device used to measure the thermal conductivity ratio is equipped with one heat flux density meter that is installed between the textile sample and the hot plate of the device. The basic principle of this research method is to create a stationary heat flow that passes through a flat sample of material of a certain thickness and to be oriented to be perpendicular to the largest faces of the sample; the heat flux density and the temperature at the opposite faces and the 
thickness of the sample are then measured. The schema of the device used is shown in Figure 2 .

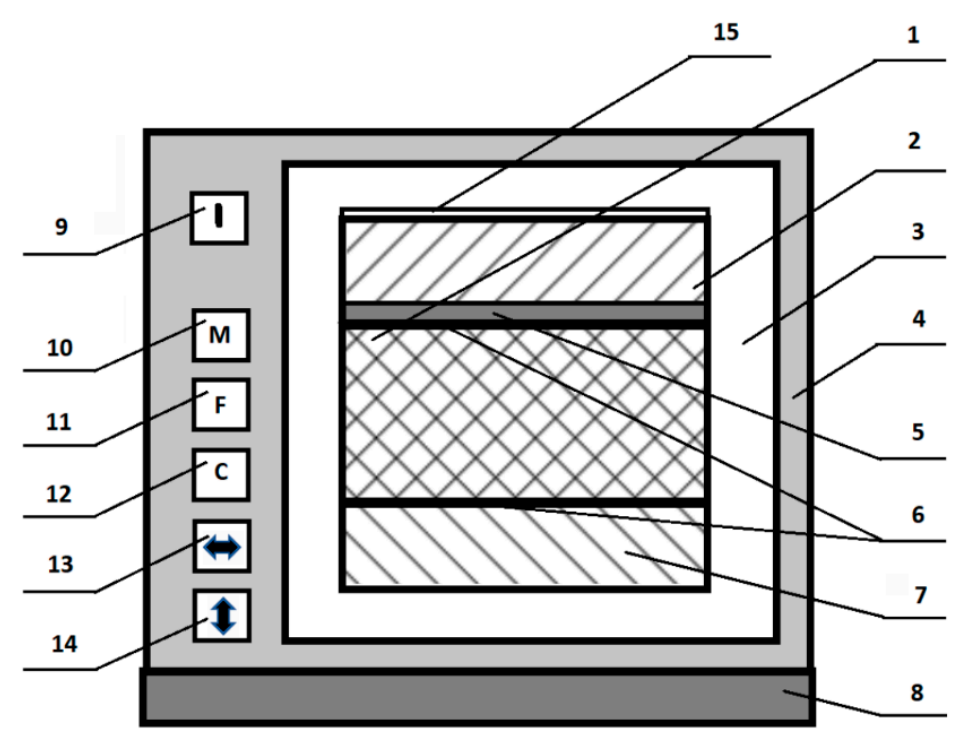

Figure 2. Schema of the apparatus for measuring the thermal conductivity of test samples: 1 , sample of the test material; 2 , heater; 3 , insulation block; 4 , housing; 5 , built-in heat meter, including heat flux density meter; 6 , temperature sensors; 7 , refrigeration unit; 8 , lower back panel (switch, fuse, power cord outlet, and heater connector); 9-14, control keyboard (9, start and end of work; 10, access to the menu and the control to save measurement results; 11 , work with the function menu, 12 , reset data; 13 and 14, control of measurement conditions); 15, height adjustment platform for measuring elements (fixing the thickness of material samples).

Platinum resistance thermometers are used to fix and control the temperature of the equipment [29]. The temperature sensor has the following parameters: type, platinum; sensitive element, film; resistance, $100 \mathrm{ohms}$; tolerance class, A; uncertainty for the temperature, $+/-(0.15+0.002 t)$, where $t$ is the temperature in degrees of Celsius; response time, $3 \mathrm{~s}$. The heat flow measurement in the experimental equipment was performed using the TEMP-3.3. The design and technical conditions for the control of the heat flow correspond to $[28,30,31]$. The thermal conditions in thermal conductivity studies depend on the thickness of the textile samples and the average thermal conductivity of the materials studied. The temperature difference between the cold and hot surfaces of the device was 5 ... $40 \mathrm{~K}[28,31]$.

The temperature and relative humidity of the room used for the present experimental research correspond to $(295 \pm 5 \mathrm{~K})$ and $(50 \pm 10 \%)$ [28].

The choice to use the studied temperature range between $+5{ }^{\circ} \mathrm{C}$ and $+25{ }^{\circ} \mathrm{C}$ is explained as follows. The upper temperature $+25^{\circ} \mathrm{C}$ is the typical indoor temperature at which the clothing is stored and accumulates heat between working shifts. The temperature $+5{ }^{\circ} \mathrm{C}$ is the typical temperature in the off-season, which is taken as the boundary between the cold and normal conditions and allows for the initial human cooling [32].

The samples have a square shape. The length of the side of the square is $250 \mathrm{~mm}$. The measurement of the sample sizes corresponds to [33]. The sample is dried to a constant weight in a drying oven. The heat flow in the experiment is considered to be stationary if the thermal conductivity values, as measured at 5 consecutive time points with an interval of $300 \mathrm{~s}$, differ from each other by less than $1 \%$ with constant signals from the measuring devices.

Measurement errors in the present experiment:

- that of temperature sensor signals: $0.5 \%$ max.;

- that of the heat flux density meter signal: $0.6 \%$ max.; 
- that of the sample thickness measurements: over $0.5 \%$ (less than $0.1 \mathrm{~mm}$ ) as the arithmetic mean of four point measurements of the sample;

- that of the pressure $0.2 \mathrm{kPa}$ [34]: $1.5 \%$ max.;

- the deviation of the front faces of a hard sample specimen from parallel alignment: $0.5 \mathrm{~mm}$ max.;

- the loss of its mass after drying: $0.1 \%$ max.

The study of the fibrous microstructure of the bonded Termofiber (No. 1 in accordance with Table 2) canvas allowed us to perform a quantitative and qualitative assessment of the $2 \mathrm{D}$ and $3 \mathrm{D}$ digital parameters of the studied fiber structure (Figure 3).

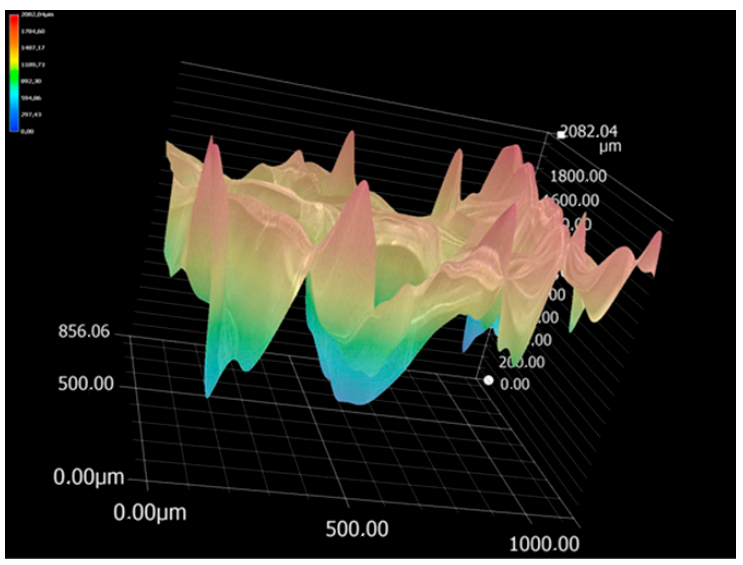

(a)

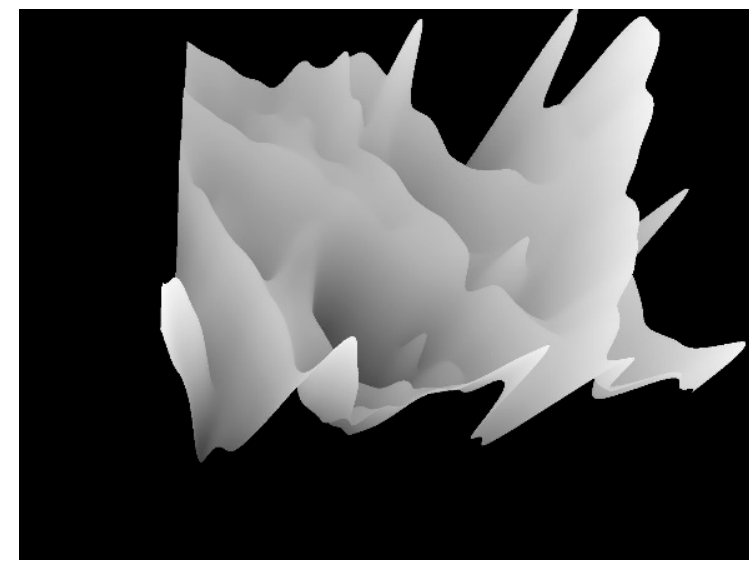

(b)

Figure 3. Analysis of the voluminous microstructure of the fibrous Termofiber canvas (300×): (a) general 3-dimensional model of the structure of the internal cavities; (b) smoothed model of the structure of the internal cavities.

Termofiber has large, internal free cavities between fibers. This allows for the design of the interface of such a structure with parts of the microencapsulated HPM.

The analysis of the Outlast textile (No. 2 in accordance with Table 2) showed that it has a three-layer structure. Each layer was examined separately from different surfaces. A cross-section was used to examine the inner layer (Figure 4).

Based on the research, we established the structural parameters of the Termofiber fibrous canvas:

- fiber diameter: 27 to $30 \mu \mathrm{m}$;

- $\quad$ cavity depth: 310 to $545 \mu \mathrm{m}$;

- $\quad$ average cavity diameter: 80 to $120 \mu \mathrm{m}$.

For the Outlast textile heat-preserving material, we have established the structural parameters as presented in Table 4.

Table 4. Characteristics of material samples for research.

\begin{tabular}{ccccc}
\hline $\begin{array}{c}\text { Object in } \\
\text { Accordance with } \\
\text { Figure 3. }\end{array}$ & $\begin{array}{c}\text { Average Diameter of } \\
\text { Heat-Accumulating } \\
\text { Capsules, } \mu \mathrm{m}\end{array}$ & $\begin{array}{c}\text { Fiber Diameter, } \\
\mu \mathrm{m}\end{array}$ & $\begin{array}{c}\text { Length of } \\
\text { Unencapsulated } \\
\text { Sections, } \mu \mathrm{m}\end{array}$ & $\begin{array}{c}\text { Even/Uneven Distribution of } \\
\text { the Encapsulated Layer and the } \\
\text { Fibers in the Fabric Structure }\end{array}$ \\
\hline (a) & 11.33 & $26 \ldots 27$ & $\begin{array}{c}\text { Microcapsule fibers are grouped } \\
\text { and oriented along the fabric } \\
\text { length. Within } 1000 \mu \mathrm{m}, \mathrm{we} \text { can } \\
\text { see an uneven distribution of the } \\
\text { bonding substance over the } \\
\text { surface area. A relative structure } \\
\text { uniformity can be assumed for } \\
\text { areas from } 2000 \mu \mathrm{m} .\end{array}$ \\
\hline
\end{tabular}


Table 4. Cont.

\begin{tabular}{|c|c|c|c|c|}
\hline $\begin{array}{l}\text { Object in } \\
\text { Accordance with } \\
\text { Figure } 3 .\end{array}$ & $\begin{array}{l}\text { Average Diameter of } \\
\text { Heat-Accumulating } \\
\text { Capsules, } \mu \mathrm{m}\end{array}$ & $\begin{array}{l}\text { Fiber Diameter, } \\
\qquad \mu \mathrm{m}\end{array}$ & $\begin{array}{c}\text { Length of } \\
\text { Unencapsulated } \\
\text { Sections, } \mu \mathrm{m}\end{array}$ & $\begin{array}{l}\text { Even/Uneven Distribution of } \\
\text { the Encapsulated Layer and the } \\
\text { Fibers in the Fabric Structure }\end{array}$ \\
\hline (b) & 11.32 & $16 \ldots 16.2$ & $285 \ldots . .430$ & $\begin{array}{l}\text { Fibers are oriented along the } \\
\text { fabric length. } \\
\text { The bonding encapsulated } \\
\text { substance is concentrated in clots } \\
\text { along the length of the material's } \\
\text { inner layer. } \\
\text { Within } 1000 \mu \mathrm{m} \text { sections, we can } \\
\text { see an uneven distribution of the } \\
\text { bonding substance over the } \\
\text { surface area. A relative structure } \\
\text { uniformity can be assumed for } \\
\text { areas from } 2000 \mu \mathrm{m} \text {. }\end{array}$ \\
\hline
\end{tabular}

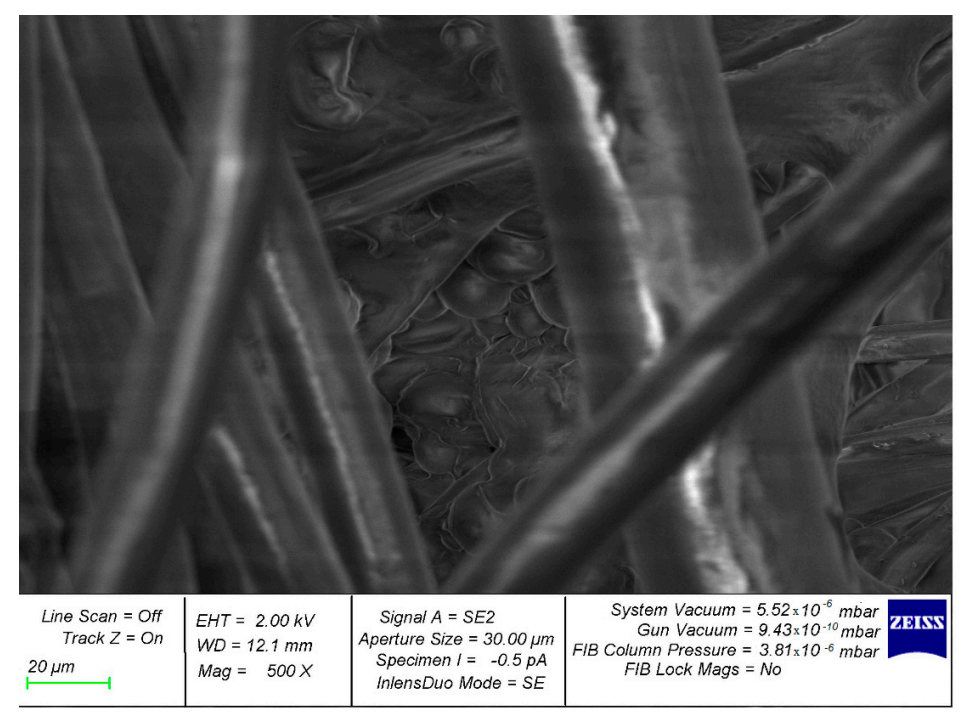

a)

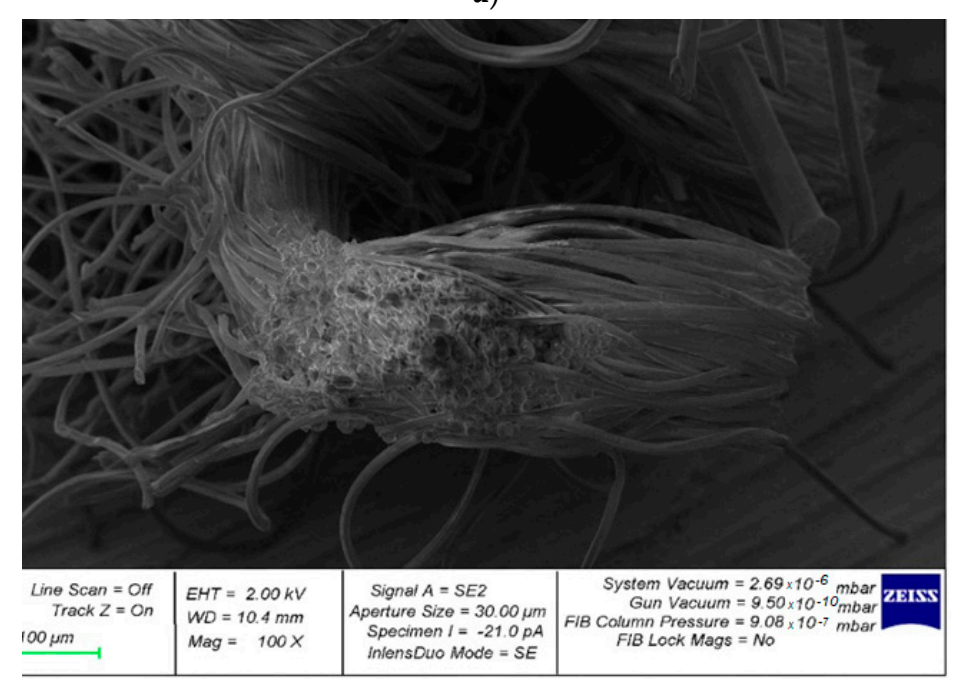

(b)

Figure 4. The microstructure of fibrous, non-woven heat-preserving Outlast textile material: (a) the microstructure for a surface with Outlast $(500 \times)$; $(\mathbf{b})$ the microstructure for the cross-section $(100 \times)$. 
The Termofiber and Outlast fiber size ratios, including the sizes of the heat-preserving capsules, have a common averaged range of values.

However, an uneven concentration of the encapsulated bonding substance in the Outlast volume does not allow us to consider it for use in a complex insulating material as elements with sizes that are similar to Termofiber fibers. Given that a relative structural regularity of the encapsulated fabric is established for sections over $2000 \mu \mathrm{m}$, it is advisable to consider the complex structure of the insulant as a combination of layers of the main Termofiber and Outlast textile in common multi-layer insulating materials [35].

To study the thermal conductivity of the compound materials of different structures, we carried out experimental studies of materials of various structures with heatpreserving components.

The obtained data were used to calculate the parts of material №2 that were integrated into the open cavities on the surface of material №1 to secure the continuity of the combined fibrous structure at the interface areas, in accordance with Figure 5.

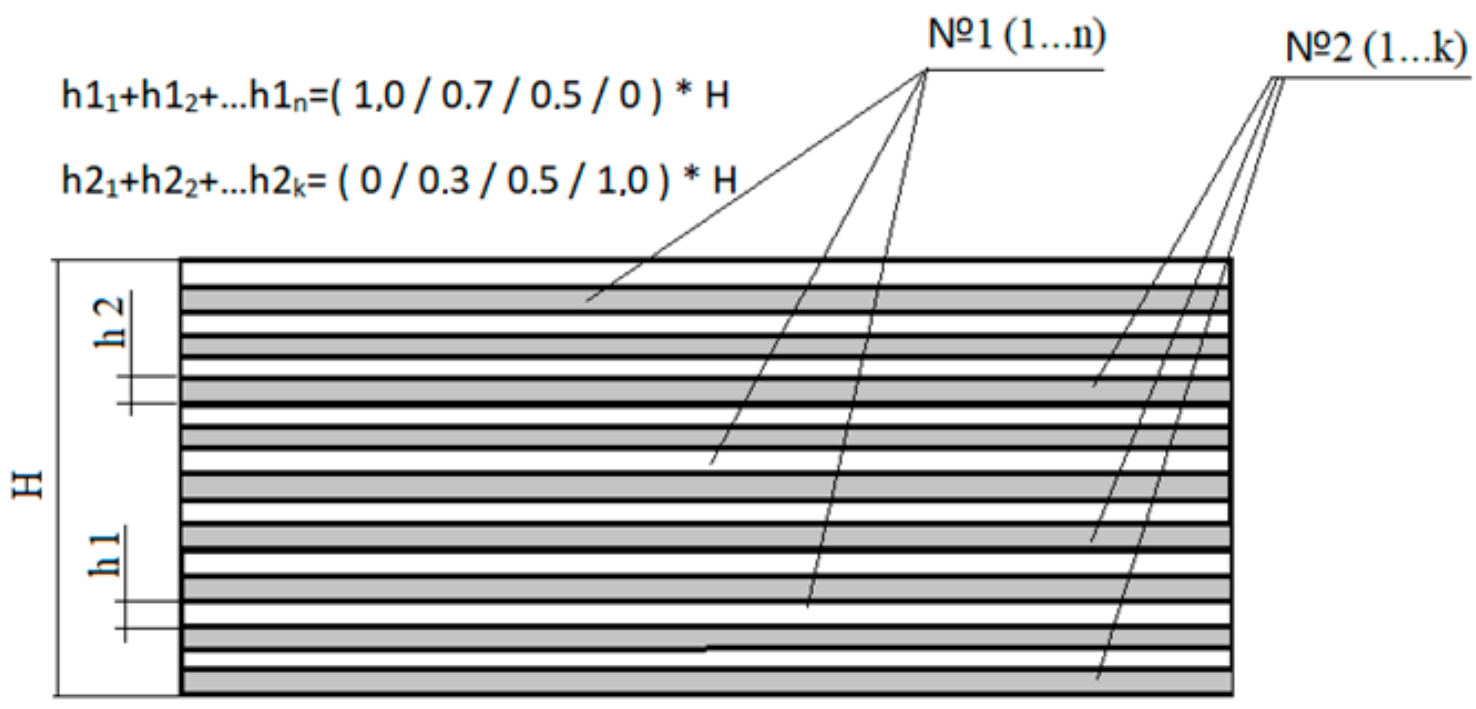

Figure 5. Scheme of complex sample materials (№1, №2 according to Table 3).

Figure 5 and Table 5 show a diagram and the parameters of the samples of complex heaters with heat-preserving materials included.

Table 5. Characteristics of the structures of the test samples.

\begin{tabular}{|c|c|c|c|c|c|}
\hline $\begin{array}{l}\text { Type of Test } \\
\text { Samples }\end{array}$ & $\begin{array}{l}\text { Fraction of Composite } \\
\text { Material Outlast Textile in } \\
\text { the Complex Material } \\
\text { (Test Samples *), \% }\end{array}$ & $\begin{array}{l}\text { Thickness of the } \\
\text { Component } \\
\text { (Material №1), mm } \\
\left(10^{-3}\right), \mathrm{h} 1 * *\end{array}$ & $\begin{array}{l}\text { Thickness of the } \\
\text { Component } \\
\text { (Material №2), mm } \\
\left(10^{-3}\right), \mathrm{h} 2 * *\end{array}$ & $\begin{array}{l}\text { Number of } \\
\text { Component Layers } \\
\text { (Material №1), } n^{* *}\end{array}$ & $\begin{array}{c}\text { Number of } \\
\text { Component Layers } \\
\text { (Material №2), } \mathrm{k} * *\end{array}$ \\
\hline 1 & 0 & 21.00 & 0 & 1 & 0 \\
\hline 2 & 30 & 2.0 & 0.85 & 5 & 5 \\
\hline 3 & 50 & 1.0 & 0.85 & 5 & 6 \\
\hline 4 & 100 & 0 & 0.85 & 0 & 1 \\
\hline
\end{tabular}

\section{Results}

Figure 6 and Table 6 show the technical parameters (the thickness, density, and percentage of the Outlast textile in a complex material) of the experimental samples of the complex materials with HPMs included. 


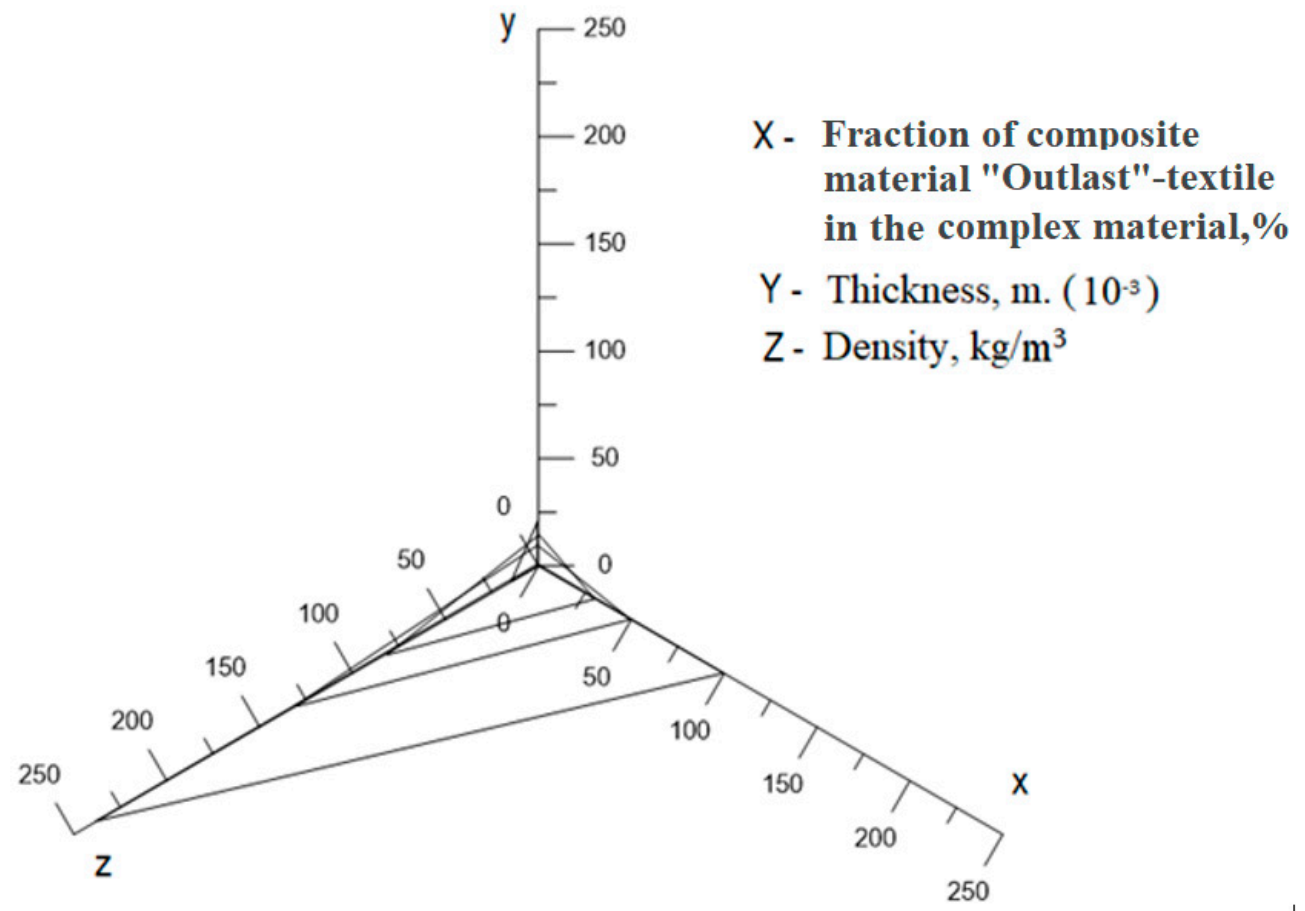

Figure 6. Parameters of material samples used for research.

Table 6. Parameters of material samples for research.

\begin{tabular}{|c|c|c|c|}
\hline № of Test Samples. & $\begin{array}{l}\text { Fraction of Composite Material Outlast } \\
\text { Textile in the Complex Material, \% * }\end{array}$ & $\begin{array}{l}\text { Thickness of Test Samples, } \\
\text { m }\left(10^{-3}\right)\end{array}$ & Density, $\mathrm{kg} / \mathrm{m}^{3}$ \\
\hline 1 & 0 & 21.00 & 14.290 \\
\hline 2 & 30 & 14.25 & 82.210 \\
\hline 3 & 50 & 10.10 & 132.021 \\
\hline 4 & 100 & 0.85 & 238.032 \\
\hline
\end{tabular}

Analysis of the research results showed that the Outlast textile material has a high density $\left(230-250 \mathrm{~kg} / \mathrm{m}^{3}\right)$ with a very small degree of thickness (samples with a thickness of $0.85 \mathrm{~mm}$ were considered). This can be explained by the concentration of polymer capsules with paraffin wax in a thin material, which is characterized by its own high density of the active substance $\left(850-930 \mathrm{~kg} / \mathrm{m}^{3}\right)$ [36]. At the same time, the Outlast textile materials with integrated heat-accumulating PCM microcapsules are characterized by a significantly lower degree of thickness compared to traditional fiber insulation cloths (at 10 times or more). The relationship between the technical parameters of the complex materials studied showed that with an increase in the density of the complex materials, there is a proportional increase in the encapsulated material Outlast textile fraction.

The combination of the Outlast textile with a lightweight polyester fiber layer that is based on Termofiber allows one to give the material heat-accumulating properties. However, for the materials in heat-protective clothing, the thermal conductivity and the thickness of the shell are of great importance.

The study of the thermal conductivity of complex insulation materials was performed for different temperature conditions. $\left(+5\right.$ and $\left.+25^{\circ} \mathrm{C}\right)$.

Figure 7 presents the results of the study of the thermal conductivity of the complex material Termofiber/Outlast textile, depending on the proportion of the heat-accumulating textile component and the temperature. 


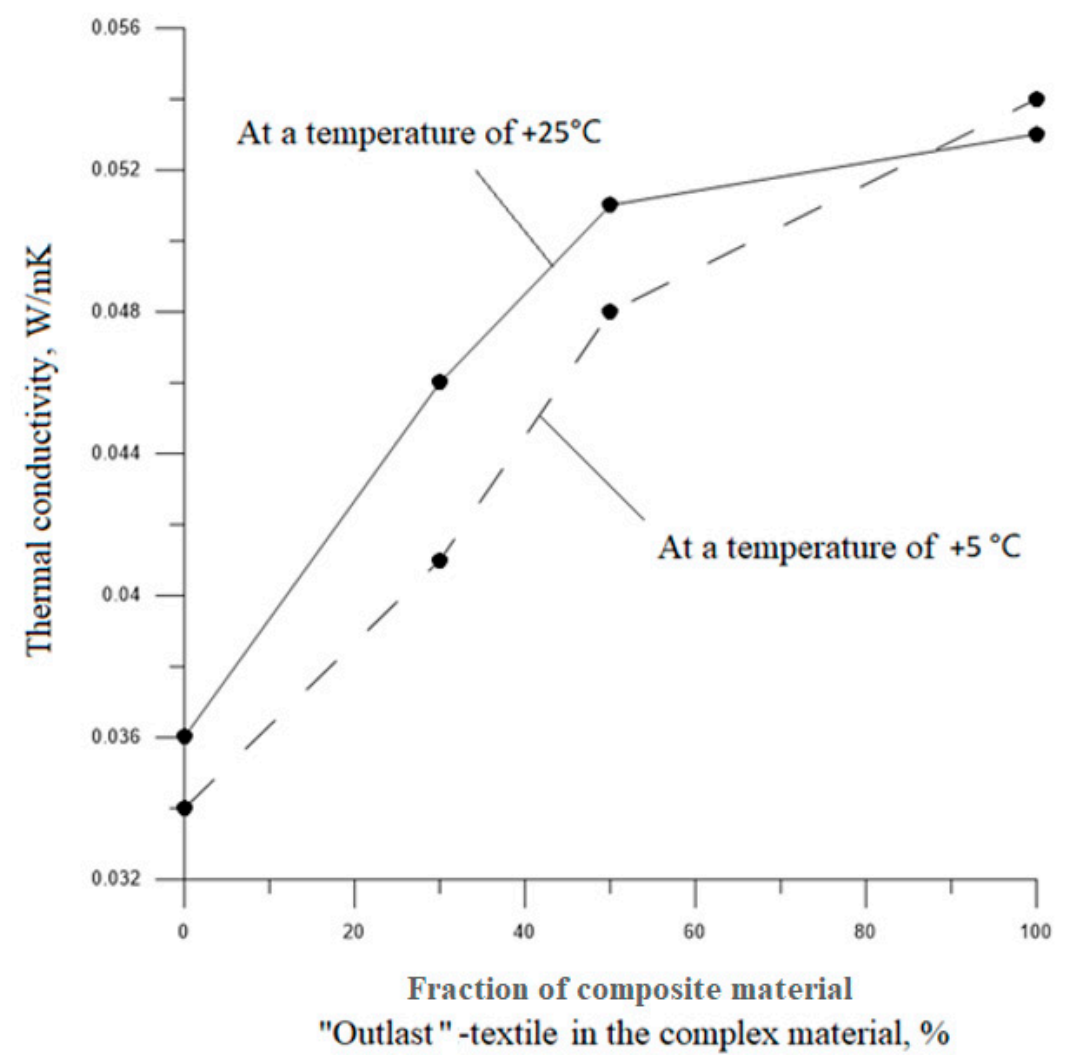

Figure 7. Thermal conductivity of the complex material Termofiber/Outlast textile depending on the proportion of the heat-accumulating textile component and the temperature.

\section{Discussion}

The results of the present study on the thermal conductivity of complex materials with different fractions of the Outlast textile in combination with the Termofiber showed a general increase in conductivity with an increasing fraction of the Outlast textile in the complex material. This can be explained by the material's own high thermal conductivity of the active component of the paraffin-based capsules. It was found that for similar complex materials at temperature conditions of $+25^{\circ} \mathrm{C}$ and $+5{ }^{\circ} \mathrm{C}$, the thermal conductivity differed by up to $10 \%$, mainly in the downward direction at a reduced temperature regime. However, the thermal conductivity of samples for different temperature conditions showed that after reaching the Outlast textile fraction in the composite material of more than $50 \%$, the thermal conductivity at elevated ambient temperatures $\left(+25^{\circ} \mathrm{C}\right)$ tends to decrease, thus improving the thermal insulation of the clothing. This feature of the materials is of interest for the use of composite fiber material for protection from high temperatures. At the same time, for low temperatures $\left(+5^{\circ} \mathrm{C}\right)$, the same composition of materials retains the dynamics of increasing thermal conductivity with an increase in the fraction of the Outlast textile and the microcapsulated paraffin, respectively. With a significant increase in the thermal conductivity of the insulation material, an increase in the overall thickness of the clothing materials is required to provide sufficient thermal insulation from the cold. However, from the point of view of the criteria of clothing ergonomics, there are restrictions on the maximum total thickness of clothing (no more than $4 \mathrm{~cm}$ ) and the corresponding thermal characteristics of textile shells (thermal resistance, no less than $0.77 \mathrm{~m}^{2} \mathrm{~K} / \mathrm{W}$; thermal conductivity, no more than $0.052 \mathrm{~W} / \mathrm{mK})[37,38]$.

The thermal resistance of the shell materials is calculated using the Formula (1):

$$
\mathrm{R}=\mathrm{d} / \lambda,
$$

where $\mathrm{R}$ is the thermal resistance in $\mathrm{m}^{2} \mathrm{~K} / \mathrm{W}$; $\mathrm{d}$ is the thickness of the fabric in $\mathrm{m}$; and $\lambda$ is the thermal conductivity in $\mathrm{W} / \mathrm{mK}$. 
The range of the thermal conductivity data obtained for a complex material has acceptable values within $85 \%$ of the Outlast textile fraction in the total material composition. However, to meet the requirements mentioned above, it is necessary to apply the criterion of reducing the thermal conductivity of the clothing materials, which should be limited to no more than $0.045 \mathrm{~W} / \mathrm{mK}$. Based on the obtained research results (Figure 6), for the development of complex materials from Termofiber + Outlast textile, the fraction of the Outlast textile component should be limited to no more than $40 \%$ for textile shells in clothing operated at a temperature of $+5{ }^{\circ} \mathrm{C}$ or below. Further conditions for determining the composition of the studied materials for clothing can be settled by taking into account the density of materials, the mass, and the general thermal insulation of clothing.

\section{Conclusions}

The base material for creating complex test samples is the Thermofiber belonging to the M2.1 category (see Figure 1). Based on the results of microstructural studies, the parameters of the elements of the encapsulated Outlast textile material were established. These elements are integrated into the open cavities of the Thermofiber insulation fabric. The resulting components of the Thermofiber material and the Outlast textile form a new complex material.

The structure, parameters, and properties of complex test samples of materials are developed and presented, taking into account warm conditions (under which phase transformations occur in the encapsulated component) and cooling conditions.

An important issue was the establishment of conditions (restrictions) for the inclusion of composite encapsulated materials in complex materials for clothing, in order to ensure the recommended thickness and thermal resistance of clothing. The thermal resistance and thickness of the clothing were used in the present work as criteria when searching for the composition of a complex material. It is established that for the design and application of protective clothing for the cold $\left(+5{ }^{\circ} \mathrm{C}\right.$ or below), the fraction of the presented heataccumulating component should not exceed $40 \%$. Such restrictions were obtained at working conditions without taking humidity into account. These restrictions allowed us to establish the basic composition of the components in the presented complex material.

The actual thermal resistance and thickness of the materials, based on the obtained thermal conductivity properties and the predicted application temperature, can be calculated. To expand the knowledge base on the thermal conductivity of the presented textile compositions, it is useful to continue research for various cooling conditions, humidity levels, and densities.

Author Contributions: Conceptualization and writing-original draft preparation, I.C. and E.L.; methodology, formal analysis, investigation, and visualization, E.L., V.V.; resources, supervision, and project administration, I.C.; writing-review and editing, N.K. All authors have read and agreed to the published version of the manuscript.

Funding: The reported study was funded by RFBR, project number 19-38-90324.

Institutional Review Board Statement: Not applicable.

Informed Consent Statement: Not applicable.

Conflicts of Interest: The authors declare no conflict of interest. The funders had no role in the design of the study; in the collection, analysis, or interpretation of data; in the writing of the manuscript, or in the decision to publish the results.

\section{References}

1. Angelova, R.A.; Reiners, P.; Georgieva, E.; Konova, H.P.; Pruss, B.; Kyosev, Y. Heat and mass transfer through outerwear clothing for protection from cold: Influence of geometrical, structural and mass characteristics of the textile layers. Text. Res. J. 2017, 87, 9. [CrossRef]

2. Zhang, X. Heat-storage and thermo-regulated textiles and clothing. In Book Smart Fibres, Fabrics and Clothing. Fundamentals and Applications. Series in Textiles; Woodhead Publishing Limited: Cambridge, UK, 2001; pp. 34-57. [CrossRef] 
3. Durakovic, B. PCMs in Separate Heat Storage Modules. In Book PCM-Based Building Envelope Systems; Springer Nature: Cham, Switzerland, 2000; pp. 121-146. [CrossRef]

4. Bird, J.E.; Humphries, T.D.; Paskevicius, M.; Poupin, L.; Buckley, C.E.; Kyosev, Y. Thermal properties of thermochemical heat storage materials. Phys. Chem. Chem. Phys. 2020, 22, 4617-4625. [CrossRef] [PubMed]

5. Ghaib, K. Latent Heat Storage: Storage Materials, Heat Transfer, and Applications. Chem. Ing. Tech. 2017, 4, 4515-4532. [CrossRef]

6. Fultz, B. Phase Transitions in Materials, 2nd ed.; Cambridge University Press: Cambridge, UK, 2020; pp. 154-196. [CrossRef]

7. Baranenko, A.V.; Kuznetsov, P.A.; Zakharova, V.Y.; Tsoy, A.P. Application of substances with phase transitions for thermal energy accumulation. Sci. Tech. J. Inf. Technol. Mech. Opt. 2018, 18, 990-1000. [CrossRef]

8. Yinga, B.A.; Kwoka, Y.L.; Lia, Y.; Yeungb, C.Y.; Zhua, Q.Y.; Lia, F.Z. Computational Investigation of thermoregulatory effects of multi-layer PCM textile assembly. In Book Computational Textile; Springer: Berlin/Heidelberg, Germany, 2007; pp. 235-245. [CrossRef]

9. Cherunova, I.V.; Kovaleva, A.A.; Nazarenko, E.V. Experimental Evaluation of Thermal Protection Properties of Volume Textile Materials. Mater. Sci. Forum 2020, 992, 916-921. [CrossRef]

10. Termofiber-Properties and Applications. Available online: https://www.roshimvolokno.ru/articles/termofiber.php (accessed on 2 March 2021).

11. Cherunova, I.; Kornev, N.; Jacobi, G.; Treshchun, I.; Gross, A.; Turnow, J.; Schreier, S.; Paschen, M. Application of Heat-Transfer Calculations and Computational Fluid Mechanics to the Design of Protective Clothing. J. Eng. Phys. Thermophys. 2014, 87, 855-863. [CrossRef]

12. Barois, P.; Demus, D.; Goodby, J.; Gray, G.W.; Vill, V. Phase Transition: Phase Transition Theories. In Book Handbook of Liquid Crystals Set; WILEY-VCH Verlag GmbH: Weinheim, Germany, 1998. [CrossRef]

13. Babaev, B.D. Principles of Heat Accumulation and Heat-Accumulating Materials in Use. High Temp. 2014, 52, 736-751. [CrossRef]

14. Salih, T.W.M.; Abdulrehman, M.A.; Al-Moameri, H.H.; Al-Kamal, A.K. Energy saving in Iraq: Waxes as phase change materials for space heating. AIP Conf. Proc. 2020, 2213, 020141. [CrossRef]

15. Moskvitina, A. Selection of heat accumulating materials for seasonal solar heating systems. Conf. Proc. Sci. Dev. New East. Eur. 2019. [CrossRef]

16. Gasanaliev, A.M.; Gamataeva, B. Yu. Heat-Accumulating Properties of Melts. Russ. Chem. Rev. 2007, 69, 179. [CrossRef]

17. Dinker, D.A.; Agarwal, M.; Agarwal, G.D. Heat storage materials, geometry and applications: A review. J. Energy Inst. 2017, 90, 1-11. [CrossRef]

18. Donskoy, A.A.; Evseeva, V.A.; Merkushova, E.V.; Shashkina, M.A. Heat-Accumulating Composition. Patent RU 2239647, 10 November 2004.

19. Kablov, E.N.; Minakov, V.T.; Donskoy, A.A.; Shashkina, M.A.; Evseeva, V.A. Heat-Accumulating Composition. Patent RU 2190656, 10 October 2002.

20. BASF to Divest Its Micronal ${ }^{\circledR}$ PCM Business to Microtek Laboratories. Available online: https://www.maisonpassive.be/IMG/ pdf/Micronal_EN.pdf (accessed on 24 March 2021).

21. PureTemp. Available online: http:/ / www.puretemp.com/how-puretemp-works (accessed on 24 March 2021).

22. Hangzhou Ruhr New Material Technology Co., Ltd. ('RuhrTech'). Available online: http:/ /www.ruhrtech.com/\#3 (accessed on 25 March 2021).

23. Schoeller ${ }^{\circledR}$-PCM. Available online: https://www.schoeller-textiles.com/en/technologies/schoeller-pcm (accessed on 24 March 2021).

24. Comfortemp ${ }^{\circledR}$ Thermal Insulation. Available online: https://apparel.freudenberg-pm.com/products/Comfortemp (accessed on 26 March 2021).

25. Outlast ${ }^{\circledR}$ Textiles. Available online: https://www.outlast.com/ (accessed on 23 March 2021).

26. Erkan, G. Enhancing The Thermal Properties of Textiles With Phase Change Materials. Res. J. Text. Appar. 2004, 8, 57-64. [CrossRef]

27. Digital Optical Microscope VHX5000 Keyence. Available online: https://sernia.ru/catalog/tsifrovye_mikroskopy_keyence/ tsifrovoy_opticheskiy_mikroskop_vhx5000_keyence/ (accessed on 27 March 2021).

28. GOST 7076 BuIlding Materials and Products. Method of Determination of Steady-State Thermal Conductivity and Thermal Re-sistance. 2000. Available online: http:/ / docs.cntd.ru/document/1200005006 (accessed on 10 March 2021).

29. Platinum Resistance Thermometer. Available online: https://www.sciencedirect.com/topics/engineering/platinum-resistancethermometer (accessed on 28 March 2021).

30. GOST 12997 SSI Products. General specifications. 1997. Available online: http://docs.cntd.ru/document/1200003319 (accessed on 10 March 2021).

31. ISO 8301. Thermal Insulation-Determination of Steady-State Thermal Resistance and Related Properties-Heat Flow Meter Apparatus. 1991. Available online: https:/ / www.sis.se/api/document/preview/912539/ (accessed on 22 May 2021).

32. ISO 11079. Ergonomics of the Thermal Environment-Determination and Interpretation of Cold Stress When Using Required Clothing Insulation (IREQ) and Local Cooling Effects. 2007. Available online: http://www.arbetsliv.eu/PPE/SS-EN_ISO_11079_ 2007.PDF (accessed on 22 May 2021). 
33. GOST 3811 Textile Materials. Textile Fabrics, Nonwonen Fabrics and Piece-Articles. Methods for Determination of Linear Dimensions Linear and Susfare Density. 2003. Available online: http://docs.cntd.ru/document/1200018455 (accessed on 15 March 2021).

34. GOST R 57632 Non-Woven Textiles Heets for Protective Clothing. Warm Textiles. Technical Requirements. Methods of Testing. 2017. Available online: http:/ / docs.cntd.ru/document/1200146752 (accessed on 16 March 2021).

35. Cherunova, I.; Osipenko, L.; Stenkina, M. Influence of structure and composition of the fibrous materials on the performance characteristics of thermal protection struc-tures with combined functions. Solid State Phenom. 2018, 284, 65-70. [CrossRef]

36. Chaichan, M.T.; Kamel, S.H.; Al-Ajeely, A.N.M. Thermal Conductivity Enhancement by using Nano-material in Phase Change Material for Latent Heat Thermal Energy Storage Systems. Saussurea 2015, 5, 48-55. Available online: https: / www.researchgate. net/publication/280923213 (accessed on 18 March 2021).

37. Cherunova, I.; Dhone, M.; Kornev, N. Coupled thermo-aerodynamical Problems in design of protection Cloth. In Proceedings of the 6th International Conference on Coupled Problems in Science and Engineering: Coupled Problems 2015, San Servolo, Venice, Italy, 18-20 May 2015; International Center for Numerical Methods in Engineering (CIMNE): Barcelona, Spain, 2015; Volume 6, pp. 1303-1311. Available online: https://www.researchgate.net/publication/283112038_Coupled_thermo-_aerodynamical_ problems_in_design_of_protection_cloth (accessed on 20 March 2021).

38. GOST 12.4.303 Occupational Safety Standards System. Protective Clothing for Low Temperatures. Technical Requirements. 2019. Available online: http:/ / docs.cntd.ru/document/1200136075/ (accessed on 20 March 2021). 